Forthcoming in

Social Policy Review 29: Analysis and Debate in Social Policy, 2017

Edited by: John Hudson, Catherine Needham and Elke Heins

\title{
Benefit tourism and EU migrant citizens: Real-world experiences
}

\author{
Rebecca Ehata and Martin Seeleib-Kaiser \\ Oxford Institute of Social Policy \\ University of Oxford
}

\begin{abstract}
This paper presents findings from research into the social rights of EU migrant citizens. Our project analysed the experiences of EU migrant citizens in Oxford and Manchester in relation to education, healthcare, benefits and housing. The findings do not substantiate the 'welfare magnet theory'; moreover, EU migrant citizens were generally unaware of their social rights before moving to the UK. Although EU migrant citizens were mostly able to exercise their social rights, we found significant instances of ignorance and discrimination by government officials. As a consequence of a (perceived) low level and quality of social and health care services in the United Kingdom, some EU migrant citizens chose to seek private provision or services in their country of origin.
\end{abstract}

Key words: EU migrant citizens; benefit tourism; social rights; discrimination; UK

\section{Introduction}

According to the 'welfare magnet theory', generous welfare states are said to be negatively affected by immigration, as migrants may be attracted by high welfare benefits or services. In a nutshell: the higher the benefits are, ceteris paribus, the higher the number of (unskilled) immigrants entering the country (Borjas 1999). In fact the dominant interpretative pattern within the political discourse leading up to the Brexit referendum was that EU migrant citizens were attracted to the UK by the relative generous welfare benefits and services. Prime Minister David Cameron in 2014 claimed:

"Someone coming to the UK from elsewhere in Europe, who's employed on the medium wage and who has 2 children back in their home country, they today will receive around f,700 per month in benefits in the UK. That is more than twice what they'd receive in Germany, and 3 times more than they would receive in France. No wonder so many people want to come to Britain" (Cameron 2014). ${ }^{1}$

However, empirical evidence on the impact of welfare state generosity on migration flows within the EU is rather mixed. De Giorgi and Pellizzari (2009) find weak evidence for welfare magnets while others reject the magnet hypothesis and argue that labour market opportunities and networks largely determine migration flows (Giulietti and Wahba 2012; Zimmermann et al. 2012; Giulietti et al. 2013; Skupnik 2014). The suggestion that EU migrant citizens will create a smaller 
net benefit (or larger net cost) in countries with tax-financed benefits, such as the UK, than in countries with predominantly insurance-based welfare states (Ruhs 2015) is also far from clear, as the financing structure is not necessarily a robust indicator for the ease of access and the level of social rights available to EU migrant citizens (Bruzelius et al. 2016). Benefits important to working-age EU migrant citizens, such as child benefit, housing allowance and in-work benefits, are largely tax financed independently of the overall financing structure of the welfare state. Research by Dustmann and Frattini (2014) found that the migration of EU citizens to the UK provides a clear economic benefit, as the average fiscal contribution of EU migrant citizens is higher than among British nationals. Spreckelsen and Seeleib-Kaiser (2016) emphasize the high employment rate among young EU migrant citizens in the UK as well as the low probability of them receiving jobseekers allowance when unemployed.

Studies investigating the welfare magnet theory are often based on macro indicators, such as social expenditure in relation to GDP, spending on unemployment benefits or replacement rates as measures for welfare state generosity, or on quantitative analyses of micro data, neglecting the de facto knowledge and experiences of EU migrant citizens with the welfare state in destination countries. In other words, research so far has paid little attention to the real-world experiences of EU migrant citizens that can provide us with hard evidence relating to the mechanisms associated with the welfare magnet theory (but cf. Spencer 2007, Kremer 2016). Do migrants actually know which benefits are available? Do they migrate because of available benefits and services or are work opportunities the more likely reason to move? Can EU migrant citizens actually access benefits, or are they denied access due to discrimination? To answer these questions we employed a qualitative research approach based on semi-structured interviews with EU migrant citizens. It was our aim to obtain insights into participants' own understanding of their social rights and their perceptions of the impact of having (or being denied) access to such rights in the UK.

We studied the experiences of EU migrant citizens from Germany, Poland, Romania and Spain living in Britain with regard to their knowledge of social rights in Britain and history of accessing them in the domains of education, healthcare, benefits and housing. The countries of origin were chosen based on the largest groups of EU migrant citizens living in Oxfordshire. Since we also wanted to account for possible differences in the location of destination in the UK, we selected Oxford and Manchester. Oxford is an affluent city with very low unemployment rates, a worldclass university and a large automotive industry. In contrast, Manchester is a de-industrialised city in Northwest England with some of the most deprived wards in the UK. A total of $56 \mathrm{EU}$ migrant citizens from Germany (13 interviews), Poland (17 interviews), Romania (9 interviews), and Spain (17 interviews) took part in the research (see Table 1 for an overview of participant profiles). Participants were recruited using snowballing, with starting points established through personal contacts, work with migrant support and advice organisations and informal approaches to likely employers of EU workers. As suggested by Triandafyllidou and Maroufof (2013), knowledge about EU citizenship rights may be associated with demographic factors such as age, educational level and nationality. Thus, the interview schedule sought to probe the impact of factors such as country of origin, level of skills and qualification, employment status, presence of dependent children and reasons for coming to the UK. Interviews were conducted between January 2015 and May 2016, in the run-up to the UK's 'Brexit' referendum. Almost all participants acknowledged an awareness of the hostility towards EU migrant citizens that characterised much of the Brexit debate, and its impact on newer arrivals in particular and their willingness to exercise their social rights should be taken into account. ${ }^{2}$ All interviews were recorded, coded and subsequently thematically analysed using NVivo. 
Table 1: Overview of interview participants' profiles

\begin{tabular}{|c|c|c|c|c|c|c|c|c|c|}
\hline & & \multicolumn{2}{|c|}{ German } & \multicolumn{2}{c|}{ Polish } & \multicolumn{2}{c|}{ Romanian* } & \multicolumn{2}{c|}{ Spanish } \\
\hline Location & Age & $\mathrm{M}$ & $\mathrm{F}$ & $\mathrm{M}$ & $\mathrm{F}$ & $\mathrm{M}$ & $\mathrm{F}$ & $\mathrm{M}$ & $\mathrm{F}$ \\
\hline Manchester & $18-24$ & & & & & & & & \\
\cline { 2 - 10 } & $25-34$ & 2 & 3 & & 2 & & & & 1 \\
\cline { 2 - 11 } & $35-44$ & 1 & & 3 & 2 & & 2 & 2 & 1 \\
\cline { 2 - 10 } & $45-54$ & & 1 & 1 & & & 2 & 1 & 1 \\
\cline { 2 - 10 } & $55-64$ & & & & & & & & 1 \\
\hline \multirow{5}{*}{ Oxford } & $18-24$ & & 1 & & & & & & 1 \\
\cline { 2 - 10 } & $25-34$ & & 1 & 1 & 3 & & 2 & 4 & 3 \\
\cline { 2 - 10 } & $35-44$ & 1 & 3 & 2 & 2 & & 2 & 1 & 1 \\
\cline { 2 - 10 } & $45-54$ & & & & 1 & & 1 & & \\
\cline { 2 - 10 } & $55-64$ & & & & & & & & \\
\hline Total & & 4 & 9 & 7 & 10 & & 9 & 8 & 9 \\
\hline
\end{tabular}

* Recruiting Romanian participants proved extremely difficult, with many people distrustful of any interest in their community following sustained hostile media attention in the months leading up to and following the lifting of transitional restrictions on Romanian and Bulgarian citizens at the end of 2013 (see Vicol and Allen 2014).

\section{Coming for work purposes}

Contrary to popular discourse in the UK, EU citizens who move to the UK do not have an unconditional right to claim social benefits or services. Rather, their rights largely depend upon their status as an economically active 'worker', self-employed person, or as an unemployed worker with retained worker status. EU citizens who are economically inactive have very few social rights outside the Member State of origin ${ }^{3}$. Thus, it is not surprising that a large majority of the predominantly young EU migrant citizens who come to Britain do so to work, and are employed in a range of economic sectors (Spreckelsen and Seeleib-Kaiser 2016). Although our sample of participants was not statistically representative of EU migrant citizens in the UK, the overwhelming majority of participants in our research was also engaged in work, in occupations ranging from au-pairs, cleaners, construction workers, and various professionals to academics. 12 participants were out of work at the time of the interview; 10 of these were actively seeking work, while the remaining two were undertaking childcare responsibilities. Participants possessed varying English language abilities and academic qualifications. Only a small number of our sample was in receipt of social benefits at the time of participation, with the exception of child benefit, which was being claimed by 21 out of 27 participants with dependent children. Three of the 56 participants were in receipt of jobseekers' allowance and three were claiming tax credits. Five people were receiving housing benefit, while four gave their housing type as 'council house'. Three participants were homeless and not in receipt of any benefits (for an overview see Table 2). The duration of residence in the UK varied widely; eight participants had been in the UK for a year or less; 17 had arrived between two and five years ago, and the remaining 31 participants had lived in the UK for between six and 15 years 
Table 2: Benefit receipt at the time of interview by length of time in UK

\begin{tabular}{|l|c|c|c|c|}
\hline Time in UK & Child benefit & Tax credits & Jobseeker's allowance & Housing benefit \\
\hline $\begin{array}{l}<12 \text { months (total }= \\
8)\end{array}$ & 1 & 0 & 0 & 0 \\
\hline $\begin{array}{l}12 \text { mths }-5 \text { yrs } \\
\text { total }=17)\end{array}$ & 5 & 2 & 1 & 3 \\
\hline $\begin{array}{l}>5 \text { years } \\
\text { total = 31) }\end{array}$ & 15 & 1 & 2 & 2 \\
\hline Total & 21 & 3 & 3 & 5 \\
\hline
\end{tabular}

Participants were keen to stress that they had been motivated to move to the UK primarily because of work; moreover, most of the people we interviewed strongly rejected the notion of EU citizens as benefit tourists by emphasizing their work contributions, their lack of knowledge regarding their potential entitlement to social rights and their cultural conditioning of selfreliance. A group of Polish and Romanian participants stressed that many benefits do not (did not) exist in their country of origin (eumc18, eumc27, eumc42, eumc47) as a result of which they took it as given that they would have to work to support themselves: 'In Poland we don't have benefits: we need to work. You don't have a choice, or you will die on the street, and no-one will care." (eumc18) Spanish citizens who participated in our research underlined their work motivation with reference to high levels of unemployment in Spain, and (for the young in particular) noted that they had not expected to be eligible for anything in the UK since financial support for jobseekers in Spain is only available to people with a previous employment record (eumc06, eumc08, eumc21, eumc22).

\section{Lack of knowledge about EU migrant citizens' social rights}

The pure availability or generosity of social benefits and services is insufficient to substantiate the welfare magnet theory, as EU migrant citizens would also need to have detailed knowledge of what would be available to them to establish the causal mechanism and causal relationship. Following the thesis to its logical conclusion, they would also need to have made a comparative evaluation of the benefits and services they would receive in the UK against what they might receive in other Member States.

However, our findings strongly indicate that knowledge of benefits is minimal, in terms of its extent and its importance in the decision-making of intra-EU migrants coming to the UK (also see Hudson et al. 2011:14 and (Dagilyte and Greenfields 2015). Very few of our participants (six out of 56) had undertaken any research to find out which specific rights would be available to them, and under what circumstances, prior to coming to the UK. Only two participants claimed to have had a more in-depth knowledge of rights before arriving in the UK: one had acquired the knowledge through previously studying EU law (eumc09), and the other (eumc47) explained that knowing she would be eligible for some benefits if she could not find well-paid work was critical for her decision to come to the UK as a single parent.

The majority of participants explained that they did not investigate rights to welfare benefits prior to their arrival in the UK because they came to work, and that they had only looked into such rights as the need arose (eumc17). Others told us that they had not had time to look into their entitlements before moving (a few participants told us that they only had two or three weeks' notice between receiving a job offer and moving to the UK), that they were not planning to stay long-term and/or only came to study, or cited youth as their reason for not finding out more (e.g. eumc10, eumc48). Lack of comparable welfare rights at home was another reason given for not researching entitlements prior to arrival in the UK (eumc35). A very small number 
of participants from Poland and Romania did not expect to have any rights at all as migrants beyond the right to work. When asked what she had known about her rights prior to arriving in the UK, one Romanian participant stated that "I had no idea and I honestly didn't expect to be entitled to something!" (eumc44). Another (Polish) participant stated that "I wasn't really expecting anything, any help: I thought I would go to work, earn the money, get a house and buy stuff" (eumc56). Some participants suggested that they simply expected the UK "as a civilised country" to have accessible healthcare and to provide school places for children (e.g. eumc01).

Healthcare was the one area that had been checked by some participants. Two German participants confirmed that they had struggled to believe that they would be able to use the NHS 'for free', as they were required to enrol in statutory health insurance schemes in Germany (eumc25, eumc26). Others acknowledged that friends and relatives already living in the UK had told them about access to the NHS (eumc35, eumc47). Since participants did not mention prior knowledge in relation to other areas of social rights, this may indicate the relative importance of health.

Finally, some of our Spanish (eumc21; eumc22) and German (eumc17; eumc52) participants, who were knowledgeable about the basics of the different welfare systems, pointed out that for those people who are eligible for unemployment and certain other benefits in their countries of origin, coming to the UK to claim benefits would not make sense, since the levels of support available are so much lower than in their countries of origin (eumc52).

With the exception of the particularly acute lack of knowledge among a group of citizens from Poland and Romania, the broad similarity in responses to questions about prior knowledge suggests that the factors of location, skill level, employment status, and reasons for coming to the UK appear to have little bearing on the extent to which individuals were aware of, or made an effort to inform themselves regarding the nature and extent of their social rights in the UK. One participant (eumc07), who is employed in a postdoctoral capacity and has lived in the UK for 10 years, was representative of many when she told us that "still now I'm not quite sure whether I'm entitled to all the benefits, like a UK national, or whether there are differences for EU citizens". She had no knowledge of the right of permanent residence that is automatically acquired after five years of legal residence in the Member State in which the EU citizen lives, and which entitles an EU migrant citizen, irrespective of economic status, to the same rights enjoyed by British citizens ${ }^{5}$.

\section{Ignorance or discrimination?}

The role of 'street-level bureaucrats' (Lipsky 1980) in determining eligibility and access to social benefits and services should not be underestimated, as frontline workers are the ones that interpret and implement the formal rules governing social policies. Based on the complexity of EU regulation and the complex transposition of EU law into national law, it is not surprising that frontline staff may struggle to keep up to date with the intricacies of who is eligible for which kind of support or service (Oliver 2013). Such uncertainty may increase the likelihood of making mistakes, as some staff admit (Rightsnet 2011). One Romanian participant told us that: "When I came here [in 2007] I found that a lot of agencies didn't have a lot of information about Romanians and their entitlements, so - it wasn't in my case but friends were refused at the beginning, yes, so there were lots of issues like that" (eumc42) ${ }^{6}$. The problem may be exacerbated in areas which have fewer migrants and thus less opportunity for staff in service provider agencies to recall and reinvigorate their knowledge of migrant entitlements. Additional pressure comes from the fact that staff working for statutory organisations have a legal duty to ensure that all recipients of resources are eligible for them, and conversely not to allocate to ineligible individuals. In a political environment of cost cutting and retrenchment as well as 
widespread allegations of 'welfare tourism', uncertainty is likely to lead to rejections of applications by staff unsure of entitlements.

Although many of our participants praised the efforts of individual frontline workers, a significant number had experienced difficulties accessing, or had been denied, their social rights as a consequence of outright discrimination. Others spoke of negative experiences by friends or other members of their networks. One Polish participant, who now undertakes both paid and voluntary work assisting her compatriots to exercise their social rights in the UK, explained that one of her clients "received a letter telling her she wasn't eligible for child benefit because Poland is not in the EU" (eumc56), while another client who was to receive an allocated social housing tenancy had her Polish ID card incorrectly refused as an identity document; after calling various government agencies and eventually persuading the official of the validity of that ID the client "was then asked to provide proof that Poland is part of the EU". In another case, a Polish family was directly discriminated against when they applied for social housing at their local council (described here by an interpreter):

"They tried and were applying twice for a council house. They had one kind of conversation with the council worker, and she wasn't very nice, and she said that because she's a teacher and her husband has a higher education degree, they are not entitled to council housing, because they can go back to Poland. Because there are English people who are kind of in greater need, they don't have any work, they don't have any education. But they complained about this lady! So then the application went to another worker and he said yes, you're entitled to this" (eumc29).

A single parent (eumc47) found herself fighting to keep benefits to which she was entitled after being made redundant from her agency job. She explained that it had taken months of correspondence and the intervention of the Citizens Advice Bureau to get official recognition of the validity of her claim. Discrimination and/or ignorance of rights extend beyond nationality: a participant of Romanian origin who had acquired British citizenship a few years previously, went to apply for Universal Credit when she recently lost her job, but was told that she could not apply because "you're not born here; universal credit is only for people who were born British citizens, born in the UK" (eumc42).

Some of these cases that we came across were the result of individual ignorance or discrimination by frontline workers, but some of the evidence suggests organisational ignorance and instances of institutional discrimination. How widespread these discriminatory practices are is unclear. Our data seems to suggest that participants with sufficient educational attainment and language proficiency are at times able to effectively challenge the wrongful decision of a local authority or public employee, whereas participants with very limited English language skills are less likely to challenge decisions without additional assistance. However, the necessary assistance to support claimants in effectively gaining access to their rights was largely cut by the Conservative-liberal government's Legal Aid, Sentencing and Punishment of Offenders Act 2012, which the Ministry of Justice itself estimated would reduce the legal aid funding available to advice charities which help individuals to appeal negative welfare decisions by more than $90 \%$ (Morris and Barr 2013: 81). Clearly, there is an urgent need for frontline staff in British service provider organisations to receive better training and clearer operational guidance on the eligibility criteria governing EU migrant citizens' social rights, though this is unlikely to be prioritised as the UK Government moves towards negotiating the country's exit from the European Union, and as yet no clear policy intentions regarding the rights of EU citizens currently resident in the UK have been set. 


\section{Going private or going 'home'}

In contrast to the notion of the welfare magnet theory or 'benefit tourism', a group of EU migrant citizens seems to be opting out of obtaining social rights from the state by sourcing private provision or by returning to their country of origin to access provision there (eumc01, eumc18, eumc23, eumc40, eumc42, eumc47, eumc53). While a few participants had acquired access to private healthcare through their employers (e.g. eumc44), some of our Polish participants had accessed the growing number of Polish private clinics that have been established in the UK since the 2004. For example, a low-waged Polish participant was paying for private dental care at a private Polish clinic in Manchester because of her concern about the poor standard of NHS dental care (eumc47). More frequently, however, our interviewees revealed practices of returning to the country of origin for partial or full medical treatment. Amongst our interviewees, reasons for deciding to go 'home' for treatment varied. In some instances it was about the impracticality of accessing care in the UK vs. the ease of access in the country of origin. For example:

'In the UK, it's quite difficult to take time off work and go and do those things. It is very bard sometimes to get to an appointment, and so I need to wait several months. But when I go to Romania on holiday, I just go straight to the doctor, pay for everything and have the treatment done, so it's very quicke" (eumc42).

An EU migrant citizen from Spain (eumc23), who has been in the UK for five years, continues to use a dentist in Spain having had difficulty getting onto the list of an NHS dentist in the UK; lack of trust in the competence of the local GPs prompted an EU migrant citizen from Poland (eumc01) to return to her country of origin to see a doctor for non-urgent medical complaints. In addition to negative opinions of the available care and competence of practitioners in the UK, a further reason given for returning to the country of origin for medical assistance concerns the importance of familiarity with the system and with individual healthcare professionals (as is the case with eumc40, who returns to Germany twice a year to use the dentist who has treated him since he was a child). Our findings are in line with Migge and Gilmartin's (2011) research in the Republic of Ireland, which identifies a number of reasons why migrants might travel back to their country of origin to access healthcare, including affordability, the perceived quality of care, bad prior experience of healthcare including excessive waiting times, as well as issues of (lack of) familiarity in terms of 'feelings of unease about local care provision due to (perceived) social, cultural, religious and linguistic differences' (Migge and Gilmartin 2011: 1148) ${ }^{7}$.

One German family experienced disruption due to the differences between the education systems in their previous country of residence (Austria) and the UK, where they were shocked to find that applying for a school place is not a matter of turning up in person on the first day of school, but rather requires a sometimes lengthy procedure with an uncertain outcome. The resolution to a missed school place for this family has been to send the child to a private school. Others did mention the possibility of opting for private education for their children based on their perception of the poor standards of state education in the UK (eumc40; eumc53).

These experiences suggest that a group of EU migrant citizens explicitly opt out of health and social services or procedures and go private or access services in their country of origin. Partly this seems to be a coping strategy by those who perceive the services and competency provided by the British welfare state to be of comparatively low quality. 


\section{Public discourse and access to social rights}

In recent years, the public and media debate in the UK has been dominated by a political discourse which characterises EU migrant citizens as benefit tourists who come to Britain to exploit or defraud the system (e.g. Balabanova and Balch 2010; Bruzelius et al. 2014). In our interviews, participants felt an obligation to reject or downplay the use of benefits as a response to the highly politicised role that the exercise of such rights plays in current media discourse. Many people stressed that they did not know anyone in their social networks who had come to rely on benefits, that all of their contacts came with the intention of working and are contributing to the system. The spectre of EU migrant citizens living on benefits was largely dismissed as the fanciful creation of the media rather than being based on reality. There was very limited acceptance of the idea that some EU citizens might in fact be exploiting free movement rights in order to access British benefits, but even in this case, the speaker emphasized such behaviour to be exceptional and not representative of EU migrant citizens in general: "Those people are ruining the reputation for those people who want to stay here. We're not like that: keep your benefits, we don't want them!" (eumc18). Some people voiced opinions which seem to chime with the rhetoric of earned rights, the need for migrants to 'pay in' before they 'take out', and proposals for deferred access to social provisions which were put forward by former Prime Minister David Cameron (2014). One participant stated:

'I don't think people should access social welfare easily in a different country. I know we are all in Europe, but each country bas its own budget and system, people to look after, so I think yes that migrants should actually take employment, and then after a period of paying taxes and working and settling, they could access welfare" (eumc42).

This finding corresponds with Kremer's (2016) research in the Netherlands, which found that some migrants also favour 'earned citizenship' rather than immediate access to social rights.

Though our participants did not come to the UK expressly to access welfare rights, some found themselves in the position of needing to apply for various types of assistance as a result of the birth of children, involuntary unemployment, ill-health or other unanticipated circumstances. Given their collective rejection of the discursive stereotype of EU migrant citizens as benefit tourists and several identifications with the negative portrayal of welfare recipients, it is unsurprising that a number of our participants, and in particular from those of Polish or Romanian nationality, intimated the conviction that they needed to justify their access to welfare. One participant who was currently in receipt of benefits as she could only work part-time explained that "I didn't want to get them ... if you get them, then you inform people that you cannot count on yourself ... this situation is very uncomfortable for me" (eumc47). A mother who had given up work to care for her daughter's serious health conditions felt the need to justify (through an interpreter) her recent application for housing benefit with this qualifier: "But she's not planning to stay on it for long, she is planning to go back to work in September" (eumc29).. Another participant declared that "This is a bit embarrassing for me, because I wanted to live my life never having to be on support, but I was unemployed for a few months, so that's when I [claimed JSA]" (eumc50).

In contrast, this was not a theme which arose automatically from our German and Spanish participants, although almost all of these were aware of the growing public discourse around EU migrants, and when probed about the effects of events such as media stories about migrants having undeserved access to welfare payments, there was a general consensus that it damaged the image of all EU migrant citizens in the UK. Most of the EU migrant citizens who we interviewed were at pains to point out the distance between their own behaviour and that of the discursive stereotype of an EU national living in the UK solely to claim benefits. For some participants this distance was linked to the stigma of dependence on welfare in general, while for 
others it came from an assertion of difference to the stereotype ${ }^{8}$. As a consequence of the political discourse and the introduction of restrictions, it seems plausible that EU migrant citizens 'underclaim' benefits, as participants emphasised that they only claim benefits when it is absolutely necessary (cf. eumc01, eumc 23 and eumc47).

\section{Conclusion}

From a methodological perspective, our research has shown how important it is not solely to rely on quantitative macro and micro analyses in assessing the welfare magnet theory, as these approaches often operate with very abstract concepts and are unable to capture the complexities of experiences and knowledge required to effectively access social rights. Research based on local implementation (e.g. see Bruzelius 2016) and individual experiences can also complement sociolegal research, which is often limited to assessing statutory entitlements and neglecting substantive access to social rights (cf. Pennings 2015). Although our research project was conducted on a relatively small scale in Oxfordshire and Manchester, we were able to identify various experiences of accessing social rights among EU migrant citizens, which are very likely to be found across the United Kingdom as well as other Member States.

Overall, we were unable to empirically identify the causal mechanisms necessary for the welfare magnet theory to be plausible. Our findings clearly show that EU migrant citizens are largely unaware of their social rights when they move to the United Kingdom. Even after living in the UK for a number of years, a relatively high degree of uncertainty with regard to social rights can be found, which might be partly the result of the complexity of the regulatory framework or of the highly salient negative political discourse in Britain. While we cannot ascertain the extent of ignorance and deliberate discrimination among government officials regarding access to social rights by EU migrant citizens, we were able to document a number of instances of such treatment. Although those with sufficient language skills and educational attainment seemed able to effectively challenge and appeal decisions, those who did not possess sufficient language skills were less likely to overcome the discriminatory practices. This is of particular significance in an environment in which central government has cut legal aid and other support which might help people to overcome discrimination. In contrast, we also came across a group of EU migrant citizens who had deliberately opted out of public provision by choosing private education and health care provision or health services in their country of origin, due to the perceived low level and quality of social and health care services in the United Kingdom. Finally, the potential consequences of the hostile public discourse towards EU migrant citizens should not be underestimated, as it is very likely to have contributed to feelings of shame and stigma as well as undeservingness among this group, and may result in EU migrant citizens not claiming benefits or services despite being legally entitled. To conclude: contrary to the welfare magnet thesis, our research clearly points towards a situation whereby various groups of EU migrant citizens underutilise the British welfare state.

Acknowledgements: We thank all participants of our research for their input, without their time and trust we would not have been able to conduct this research. We want to especially thank Suzie Drohan and Michal Gogut for their advice and overall great support for our project as well as for assistance in recruiting participants in Oxfordshire, and Amanda Jones-Said, Amanda Croome, Beth Plant and Claudia Paraschivescu for similar assistance in Manchester. We thank Elaine Chase, whose input was crucial in the initial stages of the research project, and Cecilia Bruzelius for her research assistance. Last, but not least, we are grateful for the generous funding received from the John Fell OUP Research Fund. Martin Seeleib-Kaiser thanks the WZB Berlin Social Science Centre for the generous support during his sabbatical in academic year 2016/17. 


\section{Endnotes}

\footnotetext{
${ }^{1}$ It is unclear to the authors what the basis of this calculation was.

2 Ethical approval for the fieldwork was given by the University of Oxford's Central University Research Ethics Committee, and informed written consent was obtained from all participants prior to interviews taking place. Given the politically contentious nature of EU migrant citizens' social rights in the UK, which was especially severe in the months leading up to the Brexit referendum, questions inevitably arise regarding the extent to which our participants' responses were shaped by social desirability bias. While bias may never be eliminated completely, efforts were made in the research design to minimise such effects and to destigmatise access to social rights, so that participants didn't feel obliged to under-report knowledge and use. The project introduction sheet which was given to all prospective participants framed education, housing, healthcare and social protection rights as positive aspects of EU citizenship, and the interview normalised access to those rights by focusing on the experience of applying. Questions relating to knowledge of benefits were raised after discussions about main motivations for moving to the UK. The consistency of the responses across the entire cohort, including all levels of education and national background, together with frequent explanations of finding out what support was available as situations arose, suggests that participants' stated lack of knowledge about benefits prior to arriving was reliable. Interestingly, though there has been disagreement on whether higher levels of education increase or reduce social desirability bias (Heerwig and McCabe, 2009), the lowest-educated participants were as likely as any other group to report a lack of knowledge of UK benefits before living in the UK.

${ }^{3}$ The precise regulations on eligibility for social rights are however highly complex and subject to frequent change: for more information see Pennings 2015.

${ }^{4}$ Kremer (2016) identified a similar disbelief of entitlement to welfare provisions among low-skilled Polish workers in the Netherlands.

${ }^{5}$ Article 15, The Immigration (European Economic Area) Regulations 2006, SI 20061003.

${ }^{6}$ The welfare rights of working Romanian and Bulgarian ('A2') citizens arriving in the UK between January 2007 and December 2013 were nominally the same as those of other EU migrant citizens working in the country. However, it was much more difficult for A2 citizens to qualify as 'workers'. For example, while they were permitted to work in a selfemployed capacity, most Romanian and Bulgarian ('A2') citizens (with the exception of highly skilled workers or those in a shortage occupation) were unable to take paid employment in the UK or were required to obtain worker authorisation prior to arrival. Unlike those arriving from the 2004 Central and Eastern European accession states, most A2 citizens were not permitted to enter the UK as jobseekers, a category which at that time gave access to welfare rights such as jobseeker's allowance. An A2 worker who was given permission to work but lost her job involuntarily would not retain worker status and would then lose the right to in-work benefits. Full 'worker' status was only achieved on completion of 12 months' continuous employment. See AIRE Centre (2014) for more details.

${ }^{7}$ Differences between the national healthcare systems include for example access to specialists (in the UK, this is usually obtained through a GP referral, whereas in Germany the patient makes direct contact with the specialist), or the willingness of medical practitioners to prescribe certain kinds of medication (all of our Polish participants complained that British GPs are reluctant to prescribe antibiotics, which they would expect to get readily from a Polish GP).

${ }^{8}$ The stigma of accessing benefits is not exclusive to migrants. An extensive literature documents the prevalence of stigma and shame amongst the claimants of welfare benefits (e.g. Spicker 2011; Walker 2014; Chase and Bantebya-Kyomuhendo 2015).
}

\section{References}

AIRE Centre (2014) Frequently asked questions about the rights of EE $A$ nationals to access benefits and the changes for A2 nationals from 1 January 2014, Available at: http://www.airecentre.org/data/files/TFL_Training_Materials_Feb_2014/A2_Nationals_Infor mation_Note.pdf.

Balabanova, E. and Balch, A. (2010) 'Sending and receiving: The ethical framing of intra-EU migration in the European press', European Journal of Communication, 25(4), 382-397.

Borjas, G. J. (1999) 'Immigration and welfare magnets', Journal of Labor Economics, 17(4), 607-637.

Bruzelius, C. (2016) Facilitating and restricting European social citizenship at the domestic level. Paper presented at the 23rd International Conference of Europeanists, Philadelphia, PA, April 14-16. 
Bruzelius, C., Chase, E., Hueser, C. and Seeleib-Kaiser, M. (2014) The social construction of European citizenship and associated social rights, Barnett Papers in Social Research no. 14-01, Oxford: University of Oxford.

Bruzelius, C., Chase, E. and Seeleib-Kaiser, M. (2016) 'Social rights of EU migrant citizens: Britain and Germany compared', Social Policy and Society, 15(3), 403-416.

Cameron, D. (2014) JCB Staffordshire: Prime Minister's speech. Delivered at JCB Staffordshire, 28 November 2014. Transcript of the speech as delivered. Available at: https://www.gov.uk/government/speeches/jcb-staffordshire-prime-ministers-speech . Last accessed 25th June 2015.

Chase, E. and Bantebya-Kyomuhendo, G. (2015) Poverty and shame: Global experiences, Oxford and New York: Oxford University Press.

Dagilyte, E. and Greenfields, M. (2015) 'United Kingdom welfare benefit reforms in 2013-2014: Roma between the pillory, the precipice and the slippery slope', Journal of Social Welfare and Family Law, 37(4), 476-495.

De Giorgi, G. and Pellizzari, M. (2009) 'Welfare migration in Europe', Labour Economics, 16(4): 353-363.

Dustmann, C. and Frattini, T. (2014) 'The fiscal effect of immigration to the UK', The Economic Journal, 124 (November), F593-F643.

Giulietti, C., Guzi, M., Kahanec, M. and Zimmermann, K. F. (2013) 'Unemployment benefits and immigration: evidence from the EU', International Journal of Manpower, 34(1), 24-38.

Giulietti, C. and Wahba, J. (2012) Welfare migration, IZA Discussion Paper series, Forschungsinstitut zur Zukunft der Arbeit, 6450.

Heerwig, J. and McCabe, B. (2009) 'Education and social desirability bias: The case of a black presidential candidate', Social Science Quarterly, 90(3), 674-686.

Hudson, M., Radu, D. and Phillips, J. (2011) European migrant workers' understanding and experience of the Tax Credits system, HM Revenue \& Customs Research Report 114, Bristol: Policy Studies Institute.

Kremer, M. (2016) 'Earned citizenship: Labour migrants' views on the welfare state', Journal of Social Policy, 45(3), 395-415.

Lipsky, M. (1980) Street level bureaucracy: Dilemmas of the individual in public service, New York: Russell Sage Foundation.

Migge, B. and Gilmartin, M. (2011) 'Migrants and healthcare: Investigating patient mobility among migrants in Ireland' Health and Place 17, 1144-1149.

Morris, D. and Barr, W. (2013) 'The impact of cuts in legal aid funding on charities', Journal of Social Welfare and Family Law, 35(1), 79-94.

Oliver, C. (2013) Country case study on the impacts of restrictions and entitlements on the integration of family migrants: Qualitative findings. United Kingdom. COMPAS, University of Oxford.

Pennings, F. (2015) European social security law, Antwerp: Intersentia.

Rightsnet (2011) EU migrant serious case review. Discussion forum. Available at: http://www.rightsnet.org.uk/Forums/viewthread/1598/.

Ruhs, M. (2015) 'Is unrestricted immigration compatible with inclusive welfare states? The (un)sustainability of EU exceptionalism', COMPAS Working Paper, Oxford. 
Skupnik, C. (2014) 'EU enlargement and the race to the bottom of welfare states', IZA Journal of Migration, 3(15).

Spencer, S., Ruhs, M., Anderson, B. and Rogaly, B. (2007) Migrants' lives beyond the workplace: The experiences of Central and East Europeans in the UK, York: Joseph Rowntree Foundation.

Spicker, P. (2011). Stigma and social welfare. Available from OpenAIR@RGU. [online]. Available from: http://openair.rgu.ac.uk.

Spreckelsen, T. and Seeleib-Kaiser, M. (2016) Dimensions of labour market integration among young EU migrant citizens in the UK, Barnett Papers in Social Research no. 11, Oxford: Department for Social Policy and Intervention, University of Oxford.

Triandafyllidou, A. and Maroufof, M. (2013) 'EU citizenship and intra EU mobility: A virtuous circle even in times of crisis' in De Witte, B., Héritier, A. and Trechsel, A.H. (eds), The Euro crisis and the state of European democracy, Luxembourg: Office des Publications de la Commission Européenne, pp. 370-392, available at: http://hdl.handle.net/1814/27016.

Walker, R. (2014) The shame of poverty: Global perspectives, Oxford: Oxford University Press.

Zimmermann, K. F., Kahanec, M., Giulietti, C., Guzi, M., Barrett, A. and Maître, B. (2012) Study on active inclusion of migrants, IZA Research Report 43. 